\title{
EFFECT OF Sr-SUBSTITUTION ON THE STRUCTURAL AND MAGNETOELECTRIC PROPERTIES OF Ni-Zn FERRITES
}

\author{
S. C. MAZUMDAR ${ }^{1 *}$, A. T. TRINA ${ }^{1}$, F. ALAM ${ }^{2}$, M. J. MIAH ${ }^{1}$ AND M. N. I. KHAN ${ }^{3}$ \\ ${ }^{1}$ Department of Physics, Comilla University, Cumilla-3506 \\ ${ }^{2}$ Department of Physical Sciences, Independent University, Bangladesh, Dhaka-1229, Bangladesh \\ ${ }^{3}$ Materials Science Division, Atomic Energy Centre, Dhaka 1000, Bangladesh \\ *Corresponding author e-mail: sajalf@yahoo.com
}

Received on 13.11.2019, Revised received on 25.12.2019, Accepted for publication on 29.12.2019

\begin{abstract}
Spinel type polycrystalline $\mathrm{Ni}_{0.6-x} \mathrm{Zn}_{0.4} \mathrm{Sr}_{x} \mathrm{Fe}_{2} \mathrm{O}_{4}(\mathrm{x}=0.0,0.05,0.10,0.15$ and 0.20$)$ ferrites are synthesized by solid state reaction method. X-ray diffraction (XRD) pattern reveals the formation of spinel structure with two secondary phases $\mathrm{Sr}_{2} \mathrm{FeO}_{4}$ and $\mathrm{SrFe}_{12} \mathrm{O}_{19}$ for higher concentration of $\mathrm{Sr}(0.15$ and 0.20$)$. An increase in lattice constant is observed with the increase of $\mathrm{Sr}$ content in the lattice. The density of the samples is found to decrease whereas porosity increases with the substitution of $\mathrm{Sr}^{2+}$ ions. Microstructural investigation shows that the grain size increases with the increase of $\mathrm{Sr}$ content. Magnetic hysteresis is investigated at room temperature. All the samples exhibit lower coercivity values indicating that the materials belong to the class of soft ferrites. The saturation magnetization is found to decrease with Sr content which is attributed to Néel's two sub-lattice model of ferrites. The real permeability of the samples remains almost constant up to a certain frequency and then falls rapidly. Improved dielectric constant is observed in the $\mathrm{Sr}^{2+}$ substituted samples. The electrical conduction in these ferrites is explained on the basis of hopping mechanism between the $\mathrm{Fe}^{2+}$ and $\mathrm{Fe}^{3+}$ ions.
\end{abstract}

Keywords: X-ray diffraction, initial permeability, saturation magnetization, dielectric constant.

\section{INTRODUCTION}

Ferrites are magnetic ceramics usually composed of oxides of iron and other metals having structure of mineral spinel. Among the magnetic ceramics, magnetic oxides are most important and rather the only relevant materials from the point of view of their applications. The soft ferrites have spinel type crystal structure. Spinel ferrites of different compositions have been studied and used for a long time to get useful products [1,2]. The magnetic properties of ferrite depend on cation distribution on different lattice sites, preparation condition [3], sintering temperature, sintering time, and heating and cooling rate. Solid state reaction method is one of the methods for synthesizing ferrites. In this method the sintering temperature is high. So it is responsible for the change in magnetization and resistivity of material. From the applications point of view, Ni- $\mathrm{Zn}$ ferrites represent the most important type. Different $\mathrm{Ni}-\mathrm{Zn}$ ferrites are widely used in many power electronics and magnetic devices due to their magnetic permeability and low magnetic losses $[4,5]$ and also used in electrode materials for high temperature applications because of their high thermodynamic stability, electrical resistivity, electrolytic activity and resistance to corrosion. Substituted Ni-Zn ferrites are widely used in surface mounting system such as multilayer chip inductor (MLCI) for their high permeability in the radio frequency range, low sintering temperature and relative significant resistivity. Many researchers studied on Ni-Zn ferrites and substituted $\mathrm{Ni}-\mathrm{Zn}$ ferrite in order to obtain ferrite materials having favourable magnetic and 
electrical properties with low losses especially at high frequencies [6, 7]. Gabal et al. [8] investigated a series of $\mathrm{Cr}$-substituted $\mathrm{Ni}-\mathrm{Zn}$ ferrites prepared via oxalate decomposition route to characterize the effect of $\mathrm{Cr}$-substitution on structural, magnetic and electrical properties. It was found that $\mathrm{x}$-ray densities exhibit a slight change with increasing the substitution content. The saturation magnetization, Néel temperature were found to decrease, whereas coercivity increased with increasing $\mathrm{Cr}$ content. Zinc doped nickel ferrite prepared by sol-gel method and its magnetic and electric properties were investigated by Atif et al. [9]. Slight increase in lattice parameter with increasing zinc content was reported. They also reported that the magnetization initially increased by varying zinc contents up to certain amount and afterwards it began to decrease with further increase in zinc content. It had been seen that the dielectric constant decreased with increasing frequency. Hossain et al.[10] investigated the structural and magnetic properties of various $\mathrm{Ni}$ substituted $\mathrm{Zn}_{1-x} \mathrm{Ni}_{x} \mathrm{Fe}_{2} \mathrm{O}_{4}$ synthesized by solid state reaction technique. It was observed that the mixed $\mathrm{Zn}-\mathrm{Ni}$ ferrites for small $\mathrm{Ni}$ concentration were not saturated at $10 \mathrm{~K}$ in the presence of $5 \mathrm{~T}$ field. In Ni-Zn-Mn and $\mathrm{Ni}-\mathrm{Zn}-\mathrm{Co}$ systems, the effect of $\mathrm{Mn}$ or Co substitution on the resistivity and dielectric properties have been investigated by Ramesh et al. [11]. The resistivity for the Ni$\mathrm{Zn}-\mathrm{Mn}$ system has been found to increase initially with the Mn concentration and then it decreased continuously though marginally at higher concentrations. Whereas for the $\mathrm{Ni}-\mathrm{Zn}-\mathrm{Co}$ system, the variation of resistivity is minimal at lower concentrations of Co and vary significantly with increasing Co concentration as reported by Ramesh et al. [11]. Ali et al. [12] have investigated the structural, morphological and electrical properties of Sn-substituted Ni-Zn ferrites synthesized by double sintering technique. An extra intermediate phase has been detected along with the cubic spinel phase of Ni-Zn ferrite. The effect of Sn substitution on the lattice constant didn't follow the Vegard's law [13]. It was observed that the resistivity decreases exponentially with increasing temperature indicating semiconducting behaviour of the prepared ferrites. Substitution of $\mathrm{Sn}$ in $\mathrm{Ni}-\mathrm{Zn}$ ferrite can change the grain size which in turn can enhance the initial permeability of the material suitable for power applications. On the other hand, Sn in Ni-Zn ferrite can reduce the resistivity with temperature which can make it suitable as a semiconductor material for electronic applications. In this present article $\mathrm{Sr}$ substituted $\mathrm{Ni}-\mathrm{Zn}$ ferrite is synthesized and some magnetoelectric properties such as saturation magnetization, remanant magnetization, coercive field, permeability, resistivity and dielectric constant of the samples are discussed.

\section{EXPERIMENTAL TECHNIQUES}

\subsection{Synthesis}

$\mathrm{Ni}-\mathrm{Zn}$-Sr mixed ferrite with composition $\mathrm{Ni}_{0.6-x} \mathrm{Zn}_{0.4} \mathrm{Sr}_{x} \mathrm{Fe}_{2} \mathrm{O}_{4}$ (where $x=0.0,0.05,0.10,0.15$ and 0.20 ) are prepared by standard solid state reaction method. Required stoichiometric amounts of $\mathrm{Ni}_{2} \mathrm{O}_{3}(99.99 \%), \mathrm{SrCO}_{3}(99.9 \%), \mathrm{ZnO}(99.9 \%), \mathrm{Fe}_{2} \mathrm{O}_{3}(99.9 \%)$ are mixed mechanically by milling to decrease the particle size of the powders to the micron range for the preparation of Ni-Zn-Sr ferrites. For this preparation, mortar and pestle are used for milling operation and each sample was milled for $6 \mathrm{hrs}$. The resulting powder is calcined at $800^{\circ} \mathrm{C}$ for 4 hours and grounded into fine powder by milling for 2 hours again. Grounded powder is then used in X-ray diffractometer for XRD for phase identification and Vibrating Sample Magnetometer (VSM) for magnetic properties measurement. For the investigation of surface morphology, dielectric and magnetic properties the powders are then pressed into disc and toroid shaped samples at a pressure of 2 tons $/ \mathrm{cm}^{2}$. These discs and toroids are sintered at $1250{ }^{\circ} \mathrm{C}$ for 3 hours for characterization. 


\subsection{Measurements Technique}

The X-ray diffraction (XRD) provides substantial information on the crystal structure. In order to study crystalline phases of the samples PHILIPS PW 3040 X'pert PRO X-ray diffractometer with $\mathrm{Cu}-\mathrm{K} \alpha$ radiation is used at room temperature with a range of $2 \theta$ from 20 to $70^{\circ}$. Lattice parameter $\left(a_{0}\right)$, theoretical density $\left(\rho_{\text {th }}\right)$, bulk density $\left(\rho_{B}\right)$ and porosity $(P)$ are calculated for all the samples using the following Eqs. (1)-(5).

$$
\begin{aligned}
& d_{h k l}^{2}=\frac{a^{2}}{h^{2}+k^{2}+l^{2}} \quad(\text { For cubic spinel }) \\
& F(\theta)=\frac{1}{2}\left[\left(\cos ^{2} \theta / \sin \theta\right)+\left(\cos ^{2} \theta / \theta\right]\right) \\
& \rho_{t h}=\frac{8 M}{N_{A} a_{0}^{3}} g / \mathrm{cm}^{3} \\
& P \%=\left\{\left(\rho_{t h}-\rho_{B}\right) / \rho_{t h}\right\} \times 100 \% \\
& \rho_{B}=\frac{m}{\pi t^{2} t} .
\end{aligned}
$$

Where $h, k$ and $l$ represents the crystal plane's Miller indices, $N_{A}$ denotes the number of Avogadro, $M$ means molecular weight, $a_{0}$ is the lattice constant of spinel structure, $m$ is the mass, $r$ indicates radius and $t$ signifies the pellet or ring thickness.

The grain structures of the sample are visualized under a high resolution Scanning Electron Microscope (SEM). Measurement of the magnetic hysteresis loop and the magnetic properties of the materials are performed using a Vibrating Sample Magnetometer (VSM) (Model no.: Micro Sense EV 9) within a range of $10 \mathrm{kOe}(1 \mathrm{Tesla})$. For dielectric tests, etched, well-polished pellets are used. For good electrical contact, silver paste has been used on both sides of the samples. Wayne Kerr Impedance Analyzer is used to carry dielectric measurements at room temperature in the frequency range $20 \mathrm{~Hz}$ to $100 \mathrm{MHz}$. The variation of dielectric properties (dielectric constant, dielectric loss) and magnetic properties (magnetic loss, relative quality factor, resistivity) for all the samples are measured and calculated using the following Eqs. (6)-(9).

Dielectric constant,

$$
\varepsilon^{\prime}=\frac{C}{C_{0}}
$$

Dielectric loss,

$$
\tan \delta=\frac{\varepsilon^{\prime \prime}}{\varepsilon^{\prime}}
$$

RQF,

$$
R Q F=\frac{\varepsilon}{\tan \delta}
$$


Resistivity,

$$
\rho=\frac{R A}{l}
$$

where, $C$ is the capacitance of the samples and $C_{0}$ is the capacitance of the capacitor without the dielectric materials and $C_{0}=\frac{\varepsilon_{0} A}{l}, \varepsilon_{0}$ is the permittivity of the free space and $A=\pi r^{2}$ is the area of the cross section of the pellet shaped sample, $R$ is the resistance of the sample, $l$ is the thickness of the pellets and $A$ is the surface area.

The measurement of complex permeability of the ring shaped samples are measured at room temperature in the frequency range from $100 \mathrm{~Hz}$ to $100 \mathrm{MHz}$ using the following formulas,

Real part, $\quad \mu_{i}{ }^{\prime}=\frac{L_{s}}{L_{0}}$

Imaginary part, $\quad \mu_{i}{ }^{\prime \prime}=\mu_{i}{ }^{\prime} \tan$

Where, $\mathrm{L}_{\mathrm{S}}$ is the inductance of the sample and $L_{0}=\mu_{0} N^{2} S / \pi d_{m}$ is the inductance of the winding coil without the sample that is derived from geometry of the samples, $\mathrm{N}$ represents the number of turns of the coil $(\mathrm{N}=5), S$ indicates the cross sectional area of the ring shaped samples as given below,

$$
S=d \times h
$$

and

$$
d=\frac{d_{2}-d_{1}}{2}
$$

Where, $d_{1}$ is the inner diameter and $d_{2}$ is the outer diameter, $h$ represents the height of the ring. Again, $\bar{d}$ indicates the mean diameter of the toroidal sample and can be written as,

$$
\bar{d}=\frac{d_{1}+d_{2}}{2}
$$

Then Eq.(10) can be written as

$$
\mu_{i}{ }^{\prime}=\frac{\pi L_{s} d_{m}}{\mu_{0} N^{2}\left(\frac{d_{2}-d_{1}}{2}\right) h}
$$

The relative quality factor $(\mathrm{RQF})$ is determined from the ratio $\frac{\mu_{i}^{\prime}}{\tan \delta}$ 


\section{RESULTS AND DISCUSSION}

\subsection{XRD analysis}

The XRD patterns of $\mathrm{Ni}_{0.6-x} \mathrm{Zn}_{0.4} \mathrm{Sr}_{x} \mathrm{Fe}_{2} \mathrm{O}_{4}$ for $x=0.0,0.05,0.10,0.15$ and 0.20 ferrites are recorded at room temperature by $\mathrm{X}$-ray diffraction technique using $\mathrm{CuK}_{\alpha}$ radiation $(\lambda=1.54060 \AA)$. From the analysis of (hkl) values of each peak as shown in figure 1, it is shown that the sample has cubic spinel structure. The peaks (222), (311), (222), (400), (422), (511) and (440) correspond to spinel phase. Two secondary phases are present in the XRD patterns for higher concentration of $\mathrm{Sr}(0.15$ and 0.20). We can see that there are $\mathrm{Sr}_{2} \mathrm{FeO}_{4}$ and $\mathrm{SrFe}_{12} \mathrm{O}_{19}$ impurity phases for $x=0.15$ and $x=$ 0.20 [14 -16]. The * sign indicates $\mathrm{SrFe}_{12} \mathrm{O}_{19}$ impurity phase and $\bullet$ sign indicates $\mathrm{Sr}_{2} \mathrm{FeO}_{4}$ impurity phase. The $\mathrm{Sr}$ related secondary phases increased with the dopant concentration. At higher concentration excess $\mathrm{Sr}^{2+}(1.27 \AA)$ cannot get into the crystal lattice due to larger ionic radius than $\mathrm{Ni}^{2+}(0.69 \AA)$ and accumulates at the grain boundaries as secondary phases [17].

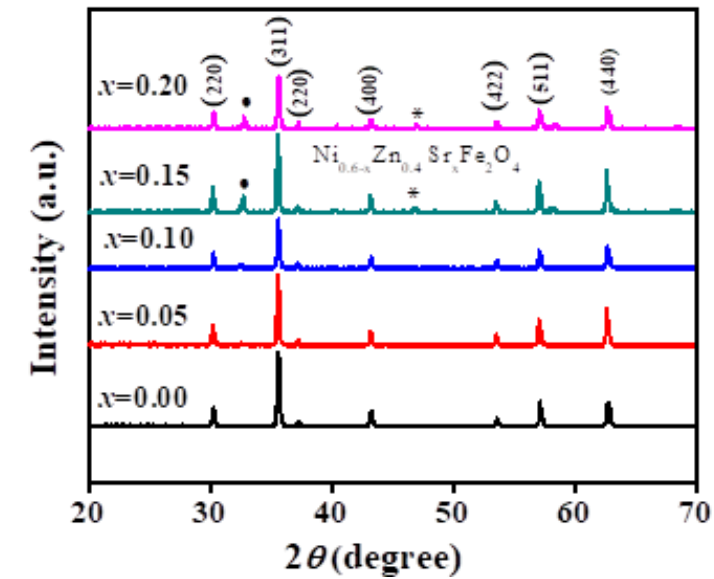

Fig. 1. XRD patterns of $\mathrm{Ni}_{0.6-x} \mathrm{Zn}_{0.4} \mathrm{Sr}_{x} \mathrm{Fe}_{2} \mathrm{O}_{4}(x=0.0,0.05,0.10,0.15$ and 0.20$)$ ferrites.

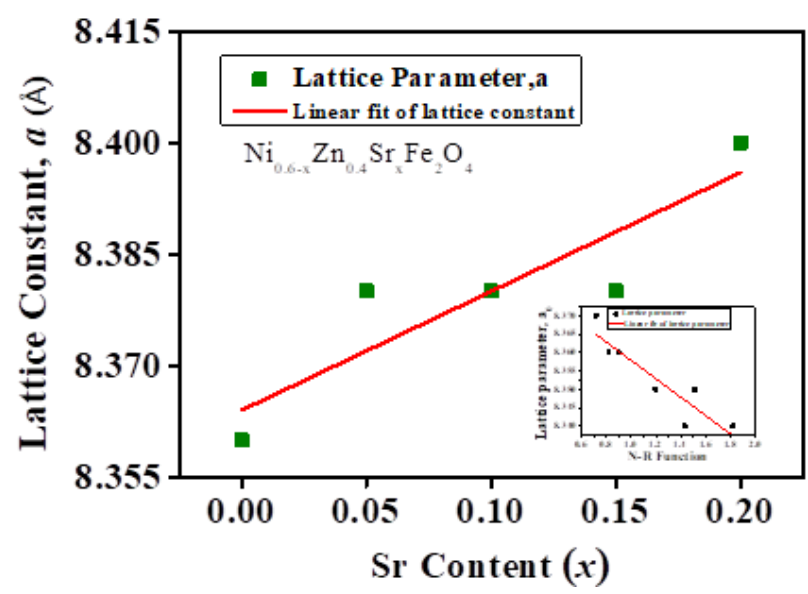

Fig. 2. Variation of lattice constant as a function of Sr content. 
Using the XRD data, the lattice constant is calculated. The accurate values of lattice constants $(a)$ for individual sample are calculated by the Nelson-Riley extrapolation method [18]. The variation of lattice constant as a function of $\mathrm{Sr}^{2+}$ content has been shown in figure 2. The inset shows the relation between $F(\theta)$ and lattice constant of the ferrite sample. The lattice constant $(a)$ is found to increase with the increase of $\mathrm{Sr}^{2+}$ ion concentration. There exist a correlation between the ionic radius and the lattice constant, the increase of lattice constant is proportional to the increase of ionic radius. The lattice constant presented does not follow the Vegard's law. From figure 2 we see that the lattice constant first increases then remains constant from $x=0.05$ to $x=0.15$ and again increases. The ionic radius of $\mathrm{Sr}^{2+}(1.27 \AA)$ is larger than that of $\mathrm{Ni}^{2+}(0.69 \AA)$ ions which results in an increase of lattice constant with $\mathrm{Sr}$ substitution. However, the excess $\mathrm{Sr}^{2+}$ ions can't get into the crystal lattice and results in the formation of $\mathrm{Sr}_{2} \mathrm{FeO}_{4}$ and $\mathrm{SrFe}_{12} \mathrm{O}_{19}$ impurity phases. It is reported that the value of lattice constant varies from 8.36 to $8.40 \AA$.

Density is an important measurement for the determination of the electrical and magnetic properties of polycrystalline ferrite sample. The bulk density is measured by using mass-volume ratio and theoretical or X-ray density is measured by using the lattice constants listed in table 1 . From figure 3 (a) it is seen that the X-ray density increases with increasing $\mathrm{Sr}$ content. This is because the molecular weight of $\mathrm{Sr}(87.62 \mathrm{~g} / \mathrm{mol})$ is larger than the molecular weight of $\mathrm{Ni}$ (58.69 $\mathrm{g} / \mathrm{mol}$ ). A significant decrease in the bulk density is observed with the substitution of $\mathrm{Sr}^{2+}$ content. This can be attributed to the fact that excess $\mathrm{Sr}$ substitution results in the $\mathrm{Sr}^{2+}$ ion separation from the spinel structure and formation of $\mathrm{Sr}_{2} \mathrm{FeO}_{4}$ and $\mathrm{SrFe}_{12} \mathrm{O}_{19}$ phases which diffuse into the crystallite boundaries and hinder the crystal growth. Moreover, the decrease in the bulk density with $\mathrm{Sr}$ content can also be explained by the presence of pores in these samples. From the figures 3 (a) and (b) it has been seen that, the x-ray density is higher than the bulk density which means that when the samples are sintered, they might contain cracks and pores on the microscopic scale and vacancies in the lattice on the atomic scale [19]. The bulk density may have these defects but the $\mathrm{X}$-ray density is precisely measured from lattice constant, volume of the unit cell is free from these defects.
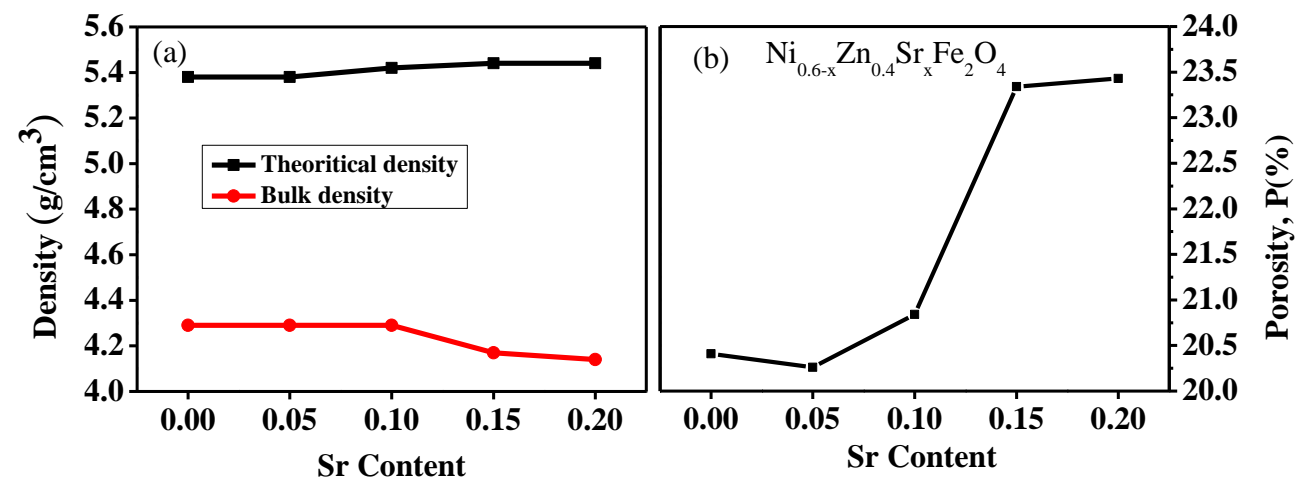

Fig. 3. (a) Density as a function of $\mathrm{Sr}$ content. (b) Porosity as a function ofSr content. 
Table 1: The lattice parameter, bulk density, X-ray density and porosity of $\mathrm{Ni}_{0.6-x} \mathrm{Zn}_{0.4} \mathrm{Sr}_{x} \mathrm{Fe}_{2} \mathrm{O}_{4}$ $(x=0.0,0.05,0.10,0.15$ and 0.20$)$ ferrites.

\begin{tabular}{lllcc}
\hline Sr content, $\boldsymbol{x}$ & Lattice parameter $(\mathbf{\AA})$ & Bulk density $\boldsymbol{\rho}_{\mathbf{B}}\left(\mathbf{g} / \mathbf{c m}^{\mathbf{3}}\right)$ & $\begin{array}{c}\mathbf{X}-\mathbf{r a y ~ d e n s i t y ~} \boldsymbol{\rho}_{\mathbf{x}} \\
\left(\mathbf{g} / \mathbf{c m}^{\mathbf{3}}\right)\end{array}$ & $\begin{array}{c}\text { Porosity, } \mathbf{P} \\
(\boldsymbol{\%})\end{array}$ \\
\hline 0.0 & 8.36 & 4.29 & 5.38 & 20.41 \\
0.05 & 8.38 & 4.29 & 5.38 & 20.26 \\
0.10 & 8.38 & 4.29 & 5.42 & 20.83 \\
0.15 & 8.38 & 4.17 & 5.44 & 23.34 \\
0.20 & 8.40 & 4.14 & 5.44 & 23.43 \\
\hline
\end{tabular}

The total porosity of the sample is the combination of the inter-granular and intra-granular porosity [20]. Thus the total porosity is

$$
\mathrm{P}=\mathrm{P}_{\text {inter }}+\mathrm{P}_{\text {intra }}
$$

The pores are left behind the rapidly moving grain boundaries and are trapped within the grains only when the grain growth rate is very high. The intra-granular porosity leading to the poor magnetic and mechanical properties is practically impossible to eliminate [21]. This might occur at high sintering temperature, prolonged sintering time and at low partial pressure of oxygen in the sintering atmosphere. At higher sintering temperature, the density is decreased because intragranular porosity increases arises from discontinuous grain growth [22]. It is clearly observed that the porosity of the sample behaves exactly opposite to the bulk density as shown in figure 3(b). Moreover, the contribution of the residual stress decreases the grain size and increases the porosity. The lattice parameter, density and porosity of the sample compositions are tabulated in table 1.

\subsection{Scanning electron microscopic analysis}

The microstructure significantly influences the magnetic and electrical properties of ferrites. Grain size is more important parameter in case of measuring the magnetic properties such as permeability. Grain growth largely depends on the grain boundary movement. Grain growth, the consequence of inter-particle mass transport, happens to be governed by the grain boundary diffusion and bimodal diffusion mechanism of lattice [23, 24].

Figure 4 shows the SEM images of various $\mathrm{Ni}_{0.6-x} \mathrm{Zn}_{0.4} \mathrm{Sr}_{x} \mathrm{Fe}_{2} \mathrm{O}_{4}$ compositions with 5000X magnification. The samples having different compositions sintered at $1250{ }^{\circ} \mathrm{C}$ are visualized under a high resolution SEM and then photographed. It has been observed from the micrographs that the samples possess fine crystalline structure. The grain size of the samples is measured by using Image $\mathbf{J}$ software. Grain sizes vary from 5.09 to $8.74 \mu \mathrm{m}$.

The grain size increases up to $x=0.15$ and then decreases for $x=0.20$. It is seen that the grains are exaggerated and size is undetermined for $x=0.05$ but it is expected that for this sample the grain size is increased as the lattice parameter for $x=0.05$ is increased. The increase in grain size might be due to the fact that the substituted $\mathrm{SrCO}_{3}$ promoted the grain growth. On the other hand, the decrease in grain size might be due to the fact that the $\mathrm{Sr}^{2+}$ resides at the grain boundary, hinders the grain growth and exerts a pressure on the unit cell. To compensate the pressure exerted by the 

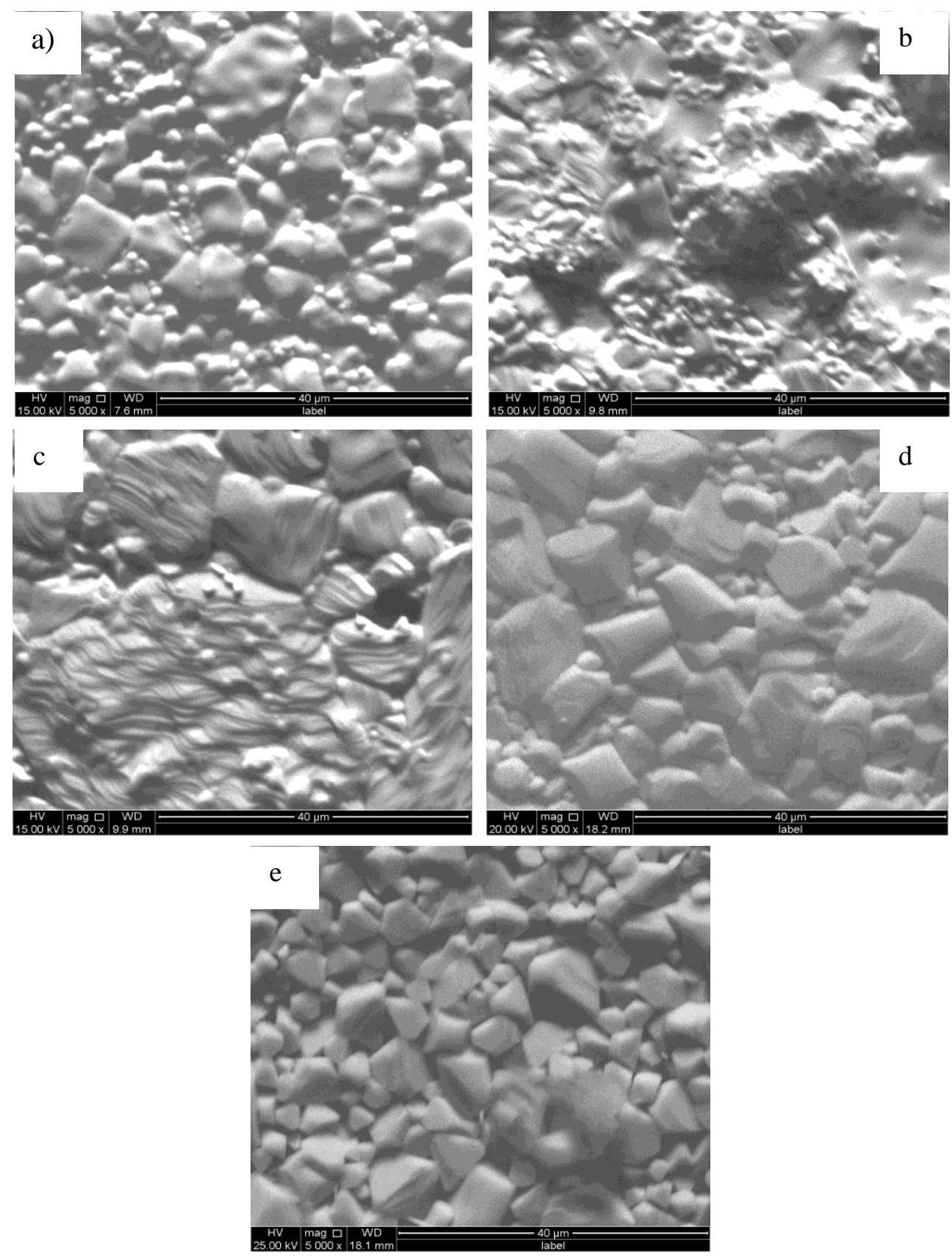

Fig. 4 Scanning electron Microscope images of $\mathrm{Ni}_{0.6-x} \mathrm{Zn}_{0.4} \mathrm{Sr}_{x} \mathrm{Fe}_{2} \mathrm{O}_{4}$ a) $x=0.0$ b) $x=0.05$, c) $x=0.10$, d) $x=0.15$ and e) $x=0.20$ 
grain boundary, shrinkage of the lattice occurs for higher $\mathrm{Sr}$ concentration and grain size decreased. Grain growth and grain boundary mobility are very closely related to each other. During the grain growth there is a competition between the driving force for grain boundary movement and retarding force exerted by the pores [8]. The smaller the grain size, the more the pores are at the grain boundary. Decrease in grain size also might be due to the reduction of oxygen vacancies [25]. The grain size reflects the presence of lesser grain boundary area. The pores are left behind the rapidly moving grain boundaries and are trapped within the grains only when the grain growth rate is very high. The intra-granular porosity which accounts for the poor mechanical properties is practically impossible to eliminate.

\subsection{Magnetic Characterization of $\mathrm{Ni}_{0.6-\mathrm{x}} \mathrm{Zn}_{0.4} \mathrm{Sr}_{x} \mathrm{Fe}_{2} \mathrm{O}_{4}$}

\subsubsection{Study of M-H loops}

Figure 5 depicts that all the samples exhibit ferromagnetic behaviour measured at room temperature. The inset is the magnetization at low fields. The room temperature magnetization curves show that hysteresis loops of the samples do not show any noticeable hysteresis effect. All samples exhibit low coercivity indicating that all the samples belong to the family of soft magnetic ferrite where saturation magnetization decreases with increase in $\mathrm{Sr}^{2+}$ concentration.

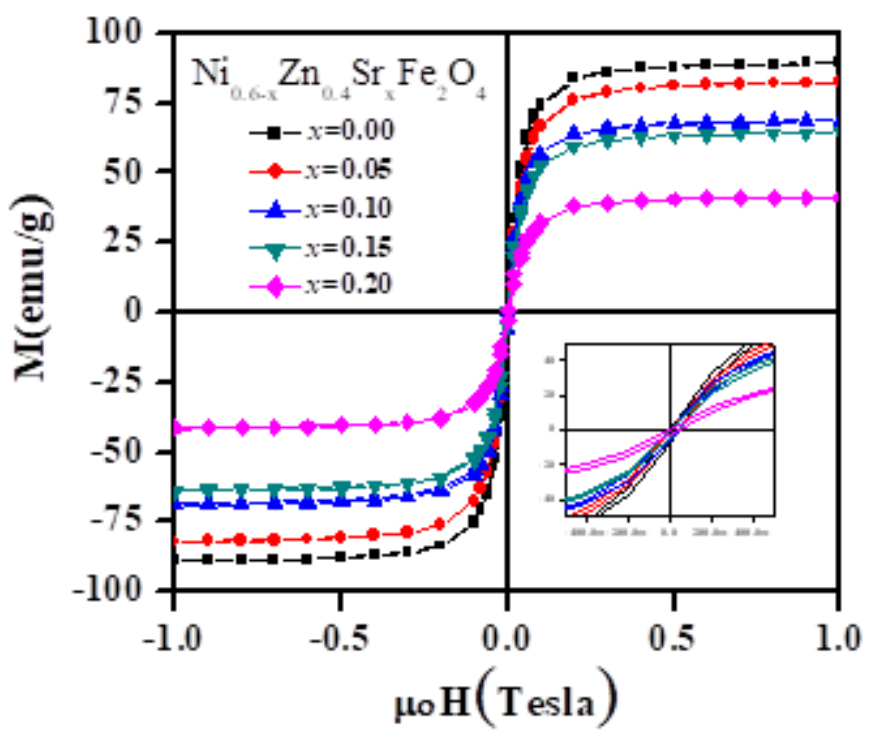

Fig. $5 \mathrm{M}$-H loop of $\mathrm{Ni}_{0.6-x} \mathrm{Zn}_{0.4} \mathrm{Sr}_{x} \mathrm{Fe}_{2} \mathrm{O}_{4}(x=0.0,0.05,0.10,0.15$ and 0.20) ferrites at room temperature.

According to Néel's two sub lattice model of ferrimagnetism [26], the saturation magnetization is given by

$\mathrm{M}_{\mathrm{S}}=\mathrm{M}_{\mathrm{B}}-\mathrm{M}_{\mathrm{A}}$

where $\mathrm{M}_{\mathrm{B}}$ and $\mathrm{M}_{\mathrm{A}}$ are the octahedral and tetrahedral sub-lattice magnetization, respectively. It is reported that $\mathrm{Sr}^{2+}$ strongly prefers the occupation of octahedral B-sites and Fe ion partially occupy 
$\mathrm{A}$ and $\mathrm{B}$ sites. When $\mathrm{Sr}^{2+}$ ions are introduced at the expense of $\mathrm{Ni}$ ions, some irons migrate from $\mathrm{B}$ to A sites. As a result, a decrease of magnetization of B sub-lattice takes place leading to decrease of the magnetization of the samples. So, the cations distribution can be written as follows:

$$
\begin{gathered}
\left(\mathrm{Zn}_{0.4} \mathrm{Fe}_{0.6}\right)\left[\mathrm{Ni}_{0.6-x} \mathrm{Sr}_{x} \mathrm{Fe}_{1.4}\right] \mathrm{O}_{4} \\
\text { (A site) } \quad \text { (B site) }
\end{gathered}
$$

\subsubsection{Study of Saturation Magnetization, Coercivity and Anisotropy Energy}

From M-H loops of the ferrite samples as shown in figure 5, saturation magnetization $\left(\mathrm{M}_{\mathrm{s}}\right)$, coercive field $\left(\mathrm{H}_{\mathrm{c}}\right)$, remanent magnetization $\left(\mathrm{M}_{\mathrm{r}}\right)$ and anisotropy constant $(\mathrm{K})$ are estimated and tabulated in table 2. It is observed that both $\mathrm{M}_{\mathrm{s}}$ and $\mathrm{M}_{\mathrm{r}}$ decrease with increase in $\mathrm{Sr}^{2+}$ content as shown in figures 6 (a) and (b). $\mathrm{Sr}^{2+}$ has strong preference in B-sites and Fe ion partially occupy $\mathrm{A}$ and $\mathrm{B}$ sites. When $\mathrm{Sr}^{2+}$ ions are incorporate for $\mathrm{Ni}$ ions, some $\mathrm{Fe}$ migrate from $\mathrm{B}$ to $\mathrm{A}$ sites. As a result, a decrease of magnetization of $B$ sub-lattices leads to decrease in $M_{s}$ of the samples. $M_{s}$ and $\mathrm{H}_{\mathrm{c}}$ depend on the defects, strain, non-magnetic atoms in the materials [27]. $\mathrm{H}_{\mathrm{c}}$ increases with the increase of $\mathrm{Sr}^{2+}$ ion concentration as shown in figure 7(a). The increase in $\mathrm{H}_{\mathrm{c}}$ depends on magneto crystalline stress, impurities concentration and the decrease of $\mathbf{M}_{\mathrm{s}}$. Increase in coercivity may be due to the sufficient defects or porosity in the sample. The $\mathrm{Sr}^{2+}$ ion having larger ionic radius enters the crystal lattice may introduce the inter stress, the formation of $\mathrm{Sr}_{2} \mathrm{FeO}_{4}$ and $\mathrm{SrFe}_{12} \mathrm{O}_{19}$ impurity phases could increase impurity concentration. It is observed from the table 2 that there is an inverse relationship between $\mathrm{M}_{\mathrm{s}}$ and $\mathrm{H}_{\mathrm{c}}$.

Anisotropy energy has been calculated using the equation:

$$
K=\left(M_{s} \times H_{c}\right) / 2
$$

From the figure 7(b), it is observed that the anisotropy constant shows a decreasing trend with the increase of $\mathrm{Sr}$ content except for $\mathrm{x}=0.10 \mathrm{~K}$ is increased for $x=0.10$ which shows the inhomogeneity of the sample and the sample required more energy to align the dipoles from easy direction to hard direction.
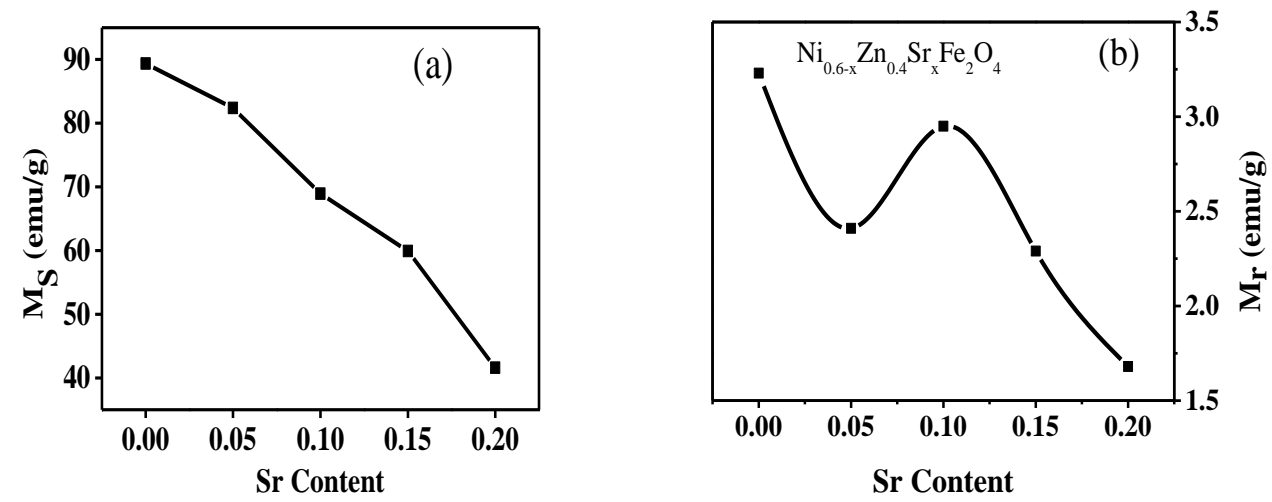

Fig. 6 (a) Saturation magnetization $\left(\mathrm{M}_{\mathrm{s}}\right)$ and (b) Remanent magnetization $\left(\mathrm{M}_{\mathrm{r}}\right)$ as a function of $\mathrm{Sr}$ content in $\mathrm{Ni}_{0.6-x} \mathrm{Zn}_{0.4} \mathrm{Sr}_{x} \mathrm{Fe}_{2} \mathrm{O}_{4}$ ferrites. 

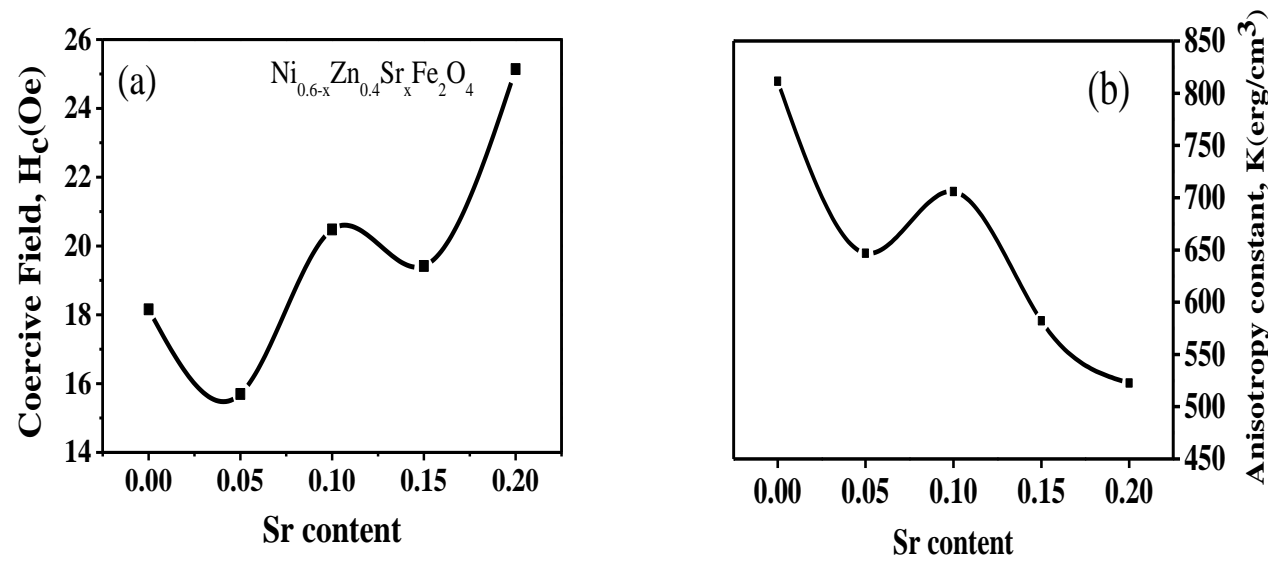

Fig. 7 (a) Coercive field $\left(\mathrm{H}_{\mathrm{C}}\right)$ and (b) anisotropy constant $(\mathrm{K})$ as a function of $\mathrm{Sr}$ content in $\mathrm{Ni}_{0.6-}$ ${ }_{x} \mathrm{Zn}_{0.4} \mathrm{Sr}_{x} \mathrm{Fe}_{2} \mathrm{O}_{4}$ ferrites.

Table 2: Calculation of Saturation magnetization, Coercivity and Anisotropy constant

\begin{tabular}{|c|c|c|c|c|}
\hline $\begin{array}{c}\text { Sr Content } \\
x \text { (mole) }\end{array}$ & $\begin{array}{c}\text { Saturation } \\
\text { magnetization } M_{s} \\
(e m u / g)\end{array}$ & $\begin{array}{c}\text { Coercivity } \\
\mathrm{H}_{\mathrm{c}}(\mathrm{Oe})\end{array}$ & $\begin{array}{c}\text { Anisotropy } \\
\text { constant } \\
\mathrm{K}\left(\mathrm{erg} / \mathrm{cm}^{3}\right)\end{array}$ & $\begin{array}{c}\text { Remanent } \\
\text { magnetization } M_{r} \\
(\mathrm{emu} / \mathrm{g})\end{array}$ \\
\hline 0.0 & 89.36 & 18.16 & 811.48 & 3.23 \\
\hline 0.05 & 82.38 & 15.70 & 646.72 & 2.41 \\
\hline 0.10 & 68.94 & 20.48 & 705.78 & 2.95 \\
\hline 0.15 & 59.93 & 19.42 & 582.04 & 2.29 \\
\hline 0.20 & 41.58 & 25.14 & 522.5 & 1.68 \\
\hline
\end{tabular}

\subsubsection{Frequency dependence of real part of initial permeability, magnetic loss and relative} quality factor

Frequency dependence of initial permeability $\mu_{i}^{\prime}$ has been measured at room temperature from 100 $\mathrm{Hz}$ to $120 \mathrm{MHz}$ for all the samples of the series $\mathrm{Ni}_{0.6-x} \mathrm{Zn}_{0.4} \mathrm{Sr}_{x} \mathrm{Fe}_{2} \mathrm{O}_{4}(x=0.0,0.05,0.10,0.15$ and 0.20 ) . From the figure 8 , it is observed that with the increasing frequency, the real part of initial permeability remains constant up to a certain frequency level and after that $\mu_{i}^{\prime}$ falls rapidly.

A large amount of $\mathrm{Ni}^{2+}$ ions occupy octahedral sub-lattice in $\mathrm{Ni}_{0.6-\chi} \mathrm{Zn}_{0.4} \mathrm{Sr}_{x} \mathrm{Fe}_{2} \mathrm{O}_{4}$ ferrites. So, the $\mathrm{Sr}^{2+}$ ion leads the $\mathrm{Ni}^{2+}$ ions to enter into the tetrahedral sub-lattice. Thus the doped sample will show the antiferromagnetic character and the dramatic decrease of initial permeability with the increase of $\mathrm{Sr}^{2+}$ may be due to this antiferromagnetic behaviour of the samples as in figure 8 . It is seen that, $\mu_{i}^{\prime}$ is high for the sample with $x=0.05$. The increase in permeability might be due to increase in grain size. The grain size effect dominates over the decrease in $\mu_{i}^{\prime}$ with the decrease in density for $x=0.05$. For other samples the decrease in $\mu_{i}^{\prime}$ with decrease in $\rho_{\mathrm{B}}$ dominates over the increase in $\mu_{i}^{\prime}$ due to grain size. There are two mechanisms which could resolve initial permeability such as the domain wall displacement and the spin rotation in the domains i.e. 


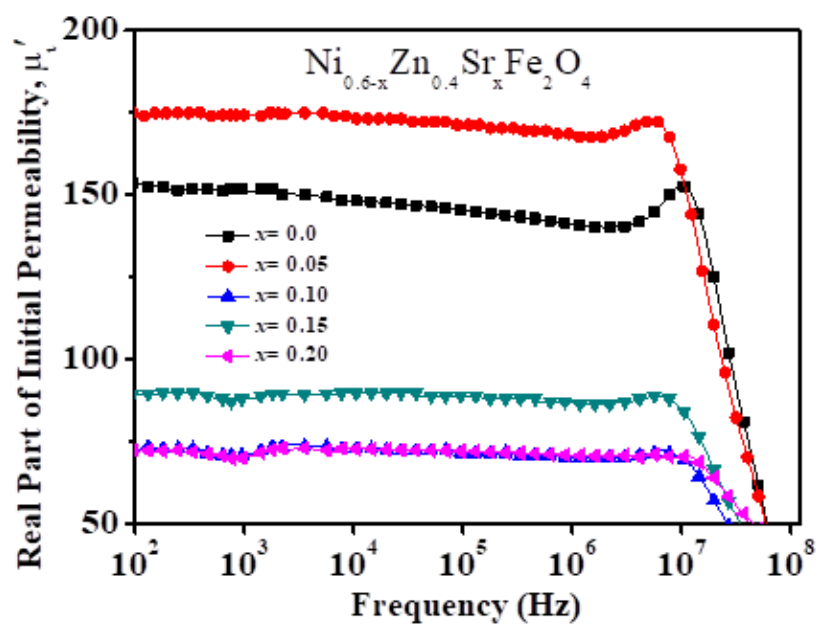

Fig. 8 Real part of initial permeability $\left(\mu_{i}^{\prime}\right)$ as a function of frequency.

The contribution from spin rotation was found smaller than the other and this is because of reversible motion of the domain walls in the weak magnetic field [28]. Domain wall is influenced by the sintering temperature and grain size. It was reported by Ross et al. [29] and Perduijin et al. [30], when grain size increases in the ferrite, the permeability increases and vice versa. The domain wall motion decreases with the decrease of grain size because the smaller grain contain lesser number of domain walls and the easy reversal of the domain walls gives initial permeability in the direction of applied magnetic field. The smaller the domain walls, the lesser is the initial permeability. The real part of initial permeability provides a precise description of the stored energy by expressing magnetic induction B in phase with the alternating magnetic field $\mathrm{H}$. The variation of $\mu_{i}^{\prime}$ can also be explained by the porosity of the samples [31]. The substituted samples are much porous than the un-substituted samples. It means that porosity increases for the increasing amount of doping content. As pores act as an impediment to the domain wall motion and induce local demagnetizing fields which results in the reduction of $\mu_{i}^{\prime}$ with the increase of $\mathrm{Sr}^{2+}$ ion concentration $[32,33]$.

The frequency dependence magnetic loss tangent $(\tan \delta)$ of the composition $\mathrm{Ni}_{0.6-\mathrm{x}} \mathrm{Zn}_{0.4} \mathrm{Sr}_{\mathrm{x}} \mathrm{Fe}_{2} \mathrm{O}_{4}$ sintered at $1250{ }^{\circ} \mathrm{C}$ at room temperature over the range $100 \mathrm{~Hz}-100 \mathrm{MHz}$ has been illustrated in figure 9 . With increase of frequency, $\tan \delta$ decreases to a certain value of frequency and then it remain constant to higher value of frequency. This phenomenon can be explained by ferrimagnetic resonance [34]. The reason behind the decrease of tan $\delta$ with increasing frequency is that, beyond certain frequency of electric field, the domain wall motion cannot follow the external electric field i.e., the domain wall motion is inhibited and the magnetization is forced to change by rotation [35]. It is observed that the value of $\tan \delta$ increases significantly with $\mathrm{Sr}$ content. Low value of magnetic loss is the main requirement for the high frequency magnetic application. The damping phenomenon along with the irreversible wall displacement and magnetic rotation can give the correct explanation about the contribution to the magnetic losses in ferrites. The loss factors are observed to have a very small value at high frequency, which is one of the criteria of the materials to be used in microwave devices [36]. 


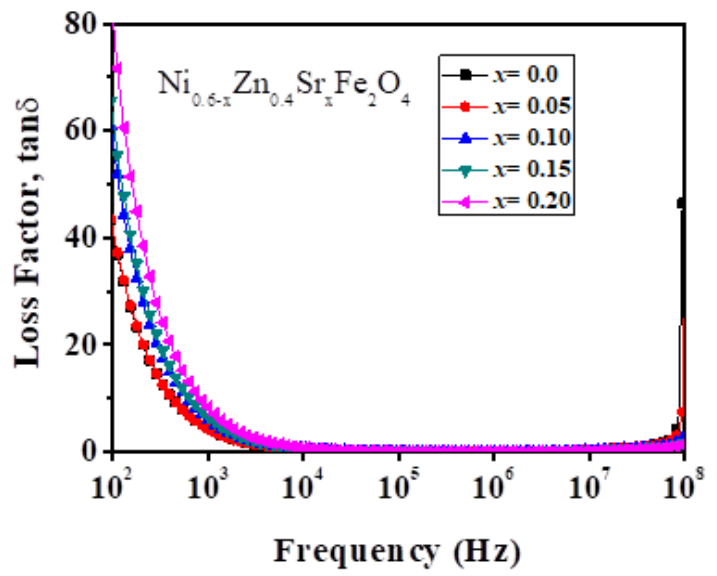

Fig. 9 Magnetic loss tangent $(\tan \delta)$ as a function of frequency.

The frequency dependence relative quality factor (RQF) of the composition $\mathrm{Ni}_{0.6-\mathrm{x}} \mathrm{Zn}_{0.4} \mathrm{Sr}_{\mathrm{x}} \mathrm{Fe}_{2} \mathrm{O}_{4}$ over the range $100 \mathrm{~Hz}-100 \mathrm{MHz}$ is illustrated in figure 10. RQF is often used as a measure of performance for inductors used in filter applications.

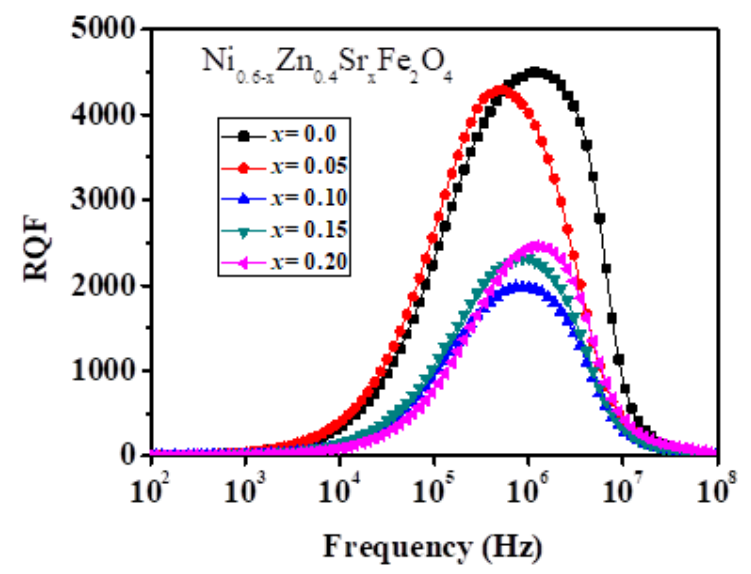

Fig. 10 Relative Quality Factor (RQF) as a function of frequency.

It is observed that RQF increases with the frequency increase and after a certain frequency it slightly decreases with increase of frequency. In fact RQF have the maximum value at that frequency level where the magnetic loss tangent has the minimum value. The lag of the domain wall motion with respect to the applied magnetic field is responsible for the loss and it is attributed 
to the various domain defects [37], including non-uniform, non-repetitive domain wall motion, wall bowing, localized variation of flux density and nucleation and annihilation of domain walls. This occurs due to the ferrimagnetic resonance within the domains at a frequency where the permeability starts to drop within the frequency [38]. RQF first rises slowly and then increases quite abruptly making a peak at a certain frequency (called resonance frequency). Improvement of $\mathrm{RQF}$ could be attributed to the Sr addition and this addition is expected to decrease the saturation magnetization.

\subsection{Electrical Characterization of $\mathrm{Ni}_{0.6-\mathrm{x}} \mathrm{Zn}_{0.4} \mathrm{Sr}_{x} \mathrm{Fe}_{2} \mathrm{O}_{4}$}

\subsubsection{Frequency dependence of resistivity}

Resistivity which is an important electrical property is an intrinsic property of magnetic material. The resistivity of $\mathrm{Ni}_{0.6-x} \mathrm{Zn}_{0.4} \mathrm{Sr}_{x} \mathrm{Fe}_{2} \mathrm{O}_{4}$ sintered at $1250{ }^{\circ} \mathrm{C}$, are calculated and plotted against frequency from $20 \mathrm{~Hz}$ to $100 \mathrm{MHz}$ as shown in figure 11. It is observed that, ac resistivity decreases with increase in $\mathrm{Sr}$ content as the dielectric constant increases with $\mathrm{Sr}$ content which means the substituted samples have high conductivity. It is also found that ac resistivity decreases with increase in frequency showing significant dispersion, which is the normal behaviour of ferrite. It is clearly observed that this dispersion is more at the low frequency side which might be due to the difference in the concentration of $\mathrm{Fe}^{3+} / \mathrm{Fe}^{2+}$ and other ions in the different samples [39].

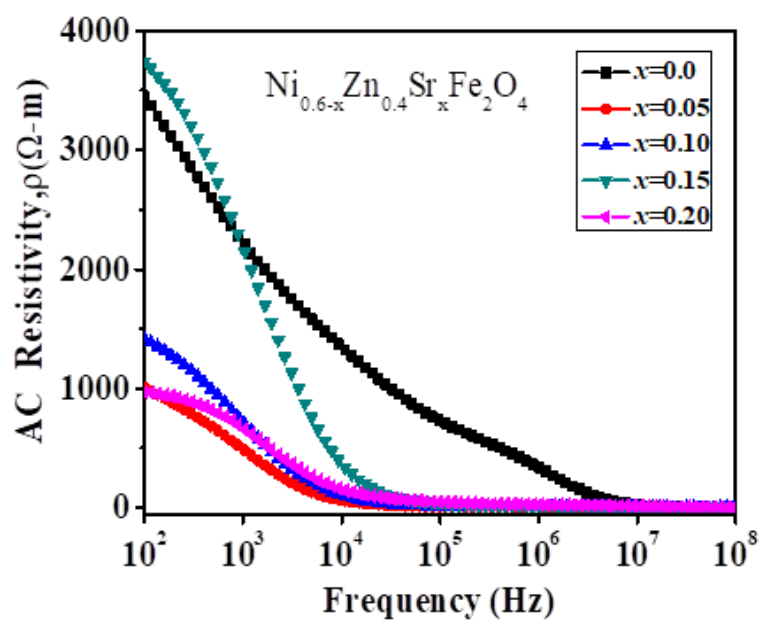

Fig. 11 Resistivity as a function of frequency.

The exchange interaction of $\mathrm{Fe}^{3+} / \mathrm{Fe}^{2+}$ in ferrites is a dominating process of conduction mechanism in which electron exchange displacement produces in the direction of applied field. In ferrites, the conduction mechanism can be explained on the basis of hopping of charge carriers between $\mathrm{Fe}^{3+}$ and $\mathrm{Fe}^{2+}$ ions on B-site [40]. The hopping of the charge carriers is developed with the increase of frequency of the applied field, which results in an increase in the conduction process thereby decreasing the resistivity. At high frequency, negligibly small values of AC resistivity is obtained and remains constant as the hopping frequency no longer follows the external applied field and lags behind it [41]. 


\subsubsection{Frequency dependence of real part of dielectric constant}

The variation of real part of dielectric constant $\left(\varepsilon^{\prime}\right)$ at room temperature with frequency range of $20 \mathrm{~Hz}$ to $100 \mathrm{MHz}$ is shown in figure 12 . From the plots it can be seen that $\varepsilon^{\prime}$ decreases rapidly with increase in frequency thereby showing dispersion in the lower frequency region and become constant at higher frequency, which is normal. At low frequencies polarizations contribute to the dielectric constant. But as the frequency increases beyond a certain limit, $\varepsilon^{\prime}$ remains almost constant because electric dipoles are not able to align themselves with the fast variation of the applied electric field and accordingly the friction between the dipoles will increase. Due to these friction dipoles dissipate energy in the form of heat and contribution from different polarizations ceases and there is a decrease in the $\varepsilon^{\prime}$. Only electronic polarization has a significant contribution to the dielectric constant at higher frequencies. The dielectric behaviour of the ferrite sample may be explained on the basis of dielectric polarization process which is similar to that of the conduction mechanism which takes place mainly by the hopping of the electrons. The observed dispersion at lower frequencies can be elucidated by using Maxwell-Wagner interfacial polarization which plays vital role in such heterogeneous system [42-45]. When $\mathrm{Sr}^{2+}$ ions are added the creation of $\mathrm{Fe}^{2+}$ give rise to electron hopping between $\mathrm{Fe}$ in +2 and +3 valance states.

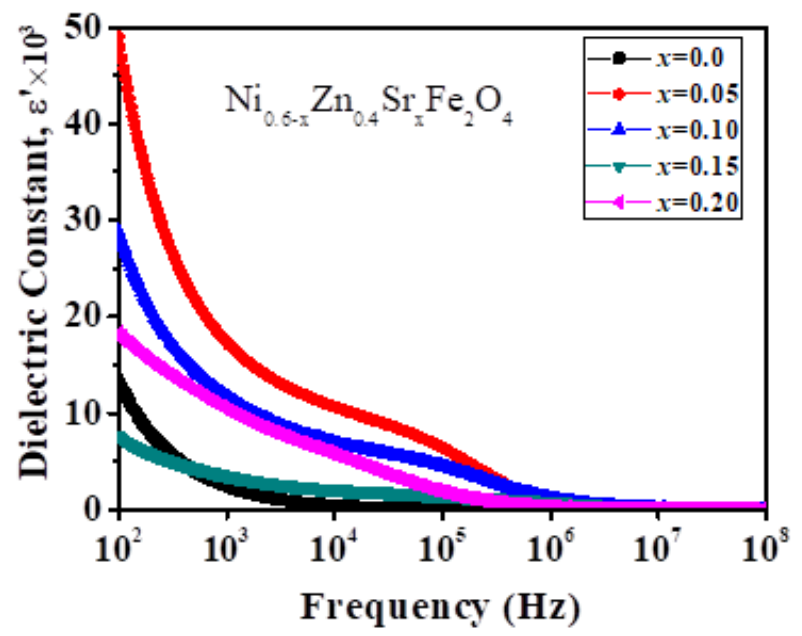

Fig. 12 Real part of dielectric constant as a function of frequency.

The higher values of the dielectric constant $\left(\varepsilon^{\prime}\right)$ observed at lower frequencies are due to the presence of heterogeneity in the composition. Heterogeneities in the samples give rise to space charge polarization and contribute towards the high values of dielectric constant. As Sr content increases, amount of space charge also increases and consequently gives a higher value of dielectric constant.

Figure 13 represents the variation of the imaginary part of dielectric constant $\left(\varepsilon^{\prime \prime}\right)$ of the compositions with frequency sintered at $1250^{\circ} \mathrm{C}$ in the frequency range $20 \mathrm{~Hz}$ to $100 \mathrm{MHz}$. It is observed that the imaginary part $\left(\varepsilon^{\prime \prime}\right)$ decreases very fast at lower frequencies with increasing $\mathrm{Sr}$ 
content which represents the presence of interfacial polarization in these compositions. The imaginary dielectric constant decreases rapidly below the resonance frequency for all samples.

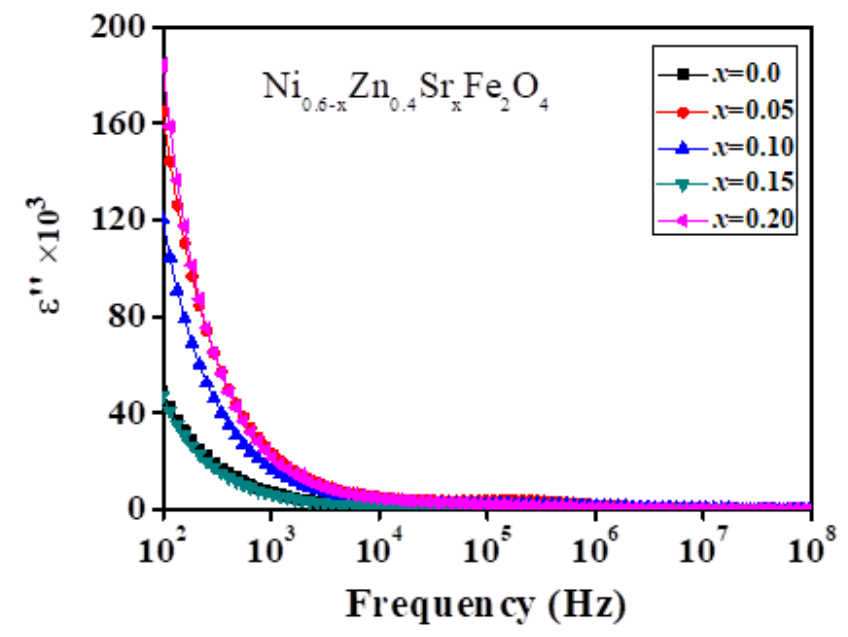

Fig. 13 Imaginary part of dielectric constant as a function of frequency.

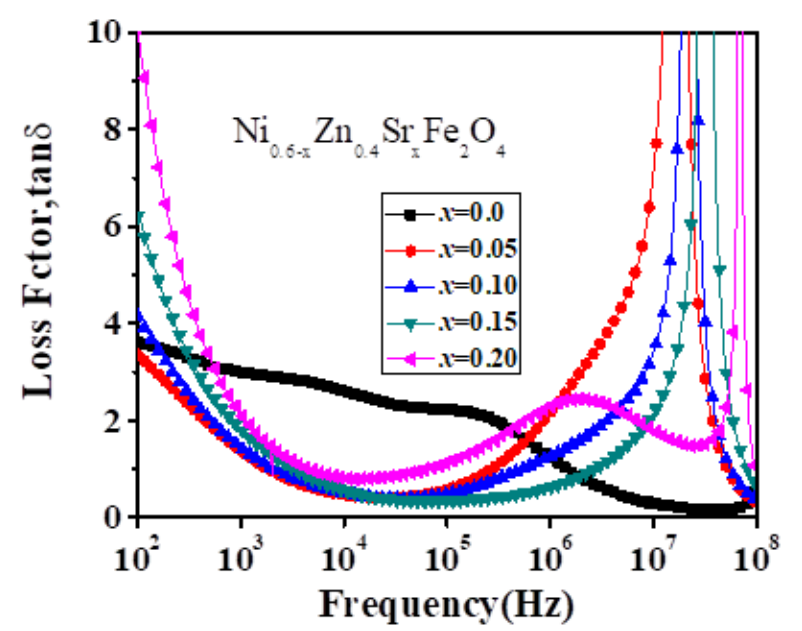

Fig. 14 Dielectric loss as a function of frequency.

Dielectric loss represents the energy dissipation in a dielectric material. It develops on account of lagging of polarization from ac applied field and depends on the grain boundaries, impurities and imperfections in the materials' crystal lattice [46, 47].

The variation of dielectric loss with frequency of the composition $\mathrm{Ni}_{0.6-x} \mathrm{Zn}_{0.4} \mathrm{Sr}_{x} \mathrm{Fe}_{2} \mathrm{O}_{4}$ is shown in figure 14 sintered at $1250^{\circ} \mathrm{C}$ in the frequency range $20 \mathrm{~Hz}$ to $100 \mathrm{MHz}$. Loss tangent is proportional to the loss of energy from the applied field in the ferrite (in fact this energy is dissipated in the form of heat) and therefore denoted as dielectric loss. At higher frequencies (1 $\mathrm{kHz}-1 \mathrm{MHz}$ ), losses are found to be lower with the increase of Sr content. At very high 
frequency $(>10 \mathrm{MHz})$ the samples exhibit a loss peak. At low frequency, space charge polarization and electric conductivity contribute to the dielectric loss. At higher frequencies, the losses are reduced and the dipoles contribute to the polarization and the reduced loss is due to the inhibition of domain wall motion and the spin rotation changes the magnetization. The $\tan \delta$ arises in materials due to the phase difference between polarization and applied field in the high frequency region. At higher frequency $(10 \mathrm{kHz}-1 \mathrm{MHz})$, the dielectric loss is small, which means the ferrite could possibly be used in practical applications such as magnetically tuneable filters and oscillators.

\section{CONCLUSIONS}

The objective of this research is to examine the effects of $\mathrm{Sr}$ substitution on Ni-Zn ferrite and hence developing its properties. The XRD patterns for the polycrystalline $\mathrm{Ni}_{0.6-x} \mathrm{Zn}_{0.4} \mathrm{Sr}_{x} \mathrm{Fe}_{2} \mathrm{O}_{4}(x=$ $0.0,0.05,0.10,0.15$ and 0.20 ) ferrites confirm the formation of cubic spinel structure. Lattice constant increases with the increase in $\mathrm{Sr}^{2+}$ content in the composition. The ionic radius of $\mathrm{Sr}^{2+}$ $(1.27 \AA)$ is larger than that of $\mathrm{Ni}^{2+}(0.69 \AA)$ ions which results in lattice parameter increase with $\mathrm{Sr}$ substitution. X-ray density increases with $\mathrm{Sr}$ content but the bulk density of ferrite decreases. Porosity follows the opposite trend that of bulk density. The increase in grain size with $\mathrm{Sr}$ content might be due to the fact that the substituted Sr promotes the grain growth. The magnetization decreases because some iron ions transferred from B to the A site leading to decrease in saturation magnetization. Moreover, the magnetic moment of $\mathrm{Sr}$ is smaller than that of $\mathrm{Ni}$ and $\mathrm{Fe}$. Coercivity increases with $\mathrm{Sr}$ doping and anisotropy is found to change significantly with $\mathrm{Sr}$ content. The increasing value of coercivity of this ferrite might make it suitable for high density recording application. The permeability first increases and then decreases with the increase of $\mathrm{Sr}$ content. $\mathrm{RQF}$ increases with increase in frequency showing a peak and then decreases with increase in frequency. The loss tangent is found to be the lowest at the frequency level where the relative quality factor is the highest. AC resistivity decreases with the increase of frequency which confirms the normal behaviour of ferrite. The dispersion of AC resistivity is more at lower frequency which could be due to the difference in the $\mathrm{Fe}^{3+}$ and $\mathrm{Fe}^{2+}$ concentrations on the octahedral site. At lower frequency region, dielectric dispersion is observed due to the MaxwellWegner interfacial type of polarization which is in agreement of Koop's phenomenological theory. Dielectric loss is especially high around the relaxation frequencies of the polarization mechanisms. At higher frequency $(>5 \mathrm{MHz})$, the dielectric loss is small and may be used in practical applications.

\section{REFERENCES}

[1] R. Peelamedu, C. Grimes, D. Agarwal, R. Roy \& P. Yadoji, Ultralow dielectric constant nickel zinc ferrites using microwave sintering, Mater. Res. 18, (10) 2292-2295 (2003).

[2] A. K. M. A. Hossain, S. T. Mahmud, M. Seki, T. Kawai, \& H. Tabata, Structural, electrical, and magnetic properties of $\mathrm{Ni}_{1-x} \mathrm{Zn}_{x} \mathrm{Fe}_{2} \mathrm{O}_{4}$, J. Mag. Magn. Mater. 312, (1) 210-219 (2007).

[3] J. Smith and H. P. J Wijn, Ferrites, Wiely London, p-1 (1995).

[4] T. Suzuki, T. Tanaka, and K. Ikemizu, High density recording capability for advanced particulate media, J. Mag. Magn. Mater. 235, 159-164 (2001),

[5] T. Giannakopoulou, L. Kompotiats, A. Kontogeorgakos, G. Kordas, Microwave behaviour of ferrites prepared via sol-gel method, J. Mag. Magn. Mater. 246, 360-365 (2002). 
[6] M. Pal, P. Brahma, D. Chakravorty, Magnetic and electrical properties of nickel-zinc ferrites doped with bismuth oxide, J. Mag. Magn. Mater. 152, 370-374 (1996).

[7] X. F. Zhu, L. F. Chen, First-principles study of the electronic and magnetic properties of a NickelZinc ferrite: $\mathrm{Zn}_{x} \mathrm{Ni}_{1-x} \mathrm{Fe}_{2} \mathrm{O}_{4}$, J. of Mag. and Magn. Mater. 323, 3138-3142 (2011).

[8] M. A. Gabal and Y. M. Al Angari, Low-temperature synthesis of nanocrystalline NiCuZn ferrite and the effect of $\mathrm{Cr}$ substitution on its electrical properties, J.Mag. Mag. Mater. 322, (20), pp. 3159-3165 (2010).

[9] M. Atif, M. Nadeem, R. Gröosssinger, R. S. Turtelli, Studies on the Magnetic, Magnetostrictive and Electrical Properties of Sol-Gel Synthesized Zn Doped Nickel Ferrite, J. Alloys Compounds, 509, 5720-5724 (2011).

[10] A. K. M. A. Hossain, M. Seki, T. Kawai, H. Tabata, Colossal magnetoresistance in spinel type $Z_{I^{-}}$ ${ }_{x} \mathrm{Ni}_{x} \mathrm{Fe}_{2} \mathrm{O}_{4}$, J. Appl. Phys. 96, 1273-1275 (2004).

[11] S. Ramesh, B. Dhanalakshmi, B. C. Sekhar, P. S. V. S. Rao and B. P. Rao, Effect of Mn/Co substitutions on the resistivity and dielectric properties of nickel-zinc ferrites, Ceram. Inter. 42, (8) 9591-9598 (2016).

[12] M. A. Ali, M. M. Uddin, M. N. I. Khan, F. U. Z. Chowdhury, S. M. Haque, Structural, morphological and electrical properties of Sn-substituted Ni-Zn ferrites synthesized by double sintering technique, $J$. Mag. Magnetic Matn, 424 , 148-154 (2017).

[13] L. Vegard, Die Konstitution Der Mischkristalle Und Die Raumf llung Der Atome. Phys. Astron, 5, 17-26 (1921).

[14] L. -Z. Li, L. Peng, X. -X. Zhong, R. Wang, and X. -Q. Tu, Structural and magnetic properties of strontium substituted NiZn ferrite nanopowders, Ceram Inter. 42, (11), pp. 13238-13241(2016).

[15] A. Loganathan and K. Kumar, Effects on structural, optical, and magnetic properties of pure and Srsubstituted $\mathrm{MgFe}_{2} \mathrm{O}_{4}$ nanoparticles at different calcination temperatures, Appl. Nanosci. 6, (5), pp. 629-639 (2015).

[16] A. C. Lima, A. P. S. Peres, J. H. Araújo, M. A. Morales, S. N. Medeiros, J. M. Soares, D. M. A. Melo, and A. S. Carriço, The effect of $\mathrm{Sr}^{2+}$ on the structure and magnetic properties of nanocrystalline cobalt ferrite, Materi. Lettr. 145, 56-58 (2015).

[17] M. A. Khan, M. U. Islam, M. Ishaque, and I. Z. Rahman, Effect of Tb substitution on structural, magnetic and electrical properties of magnesium ferrites, Ceramics Inter. 37, (7), 2519-2526 (2011).

[18] J. B. Nelson and D. P. Riley, An experimental investigation of extrapolation methods in derivation of accurate unit-cell dimensions of crystals, Proceedi. of the Phys. Soc. 57, (3), 160-177 (1945).

[19] B. D. Cullity and R. Smoluchowski, Elements of X-Ray Diffraction, Physics Today, 10, (3), pp. 5050 (1957).

[20] A. A. Sattar, H. M. El-Sayed, K. M. El-Shokrofy, and M. M. El-Tabey, Effect of Manganese Substitution on the Magnetic Properties of Nickel-Zinc Ferrite, J. Mater Engin. Perform., 14, (1), 99103 (2005).

[21] R. Valenzuela, Magnetic Ceramics, Cambridge University Press, Cambridge (1994).

[22] S. T. Mahmud, A. K. M. Akther Hossain, A. K. M. Abdul Hakim, M. Seki, T. Kawai, and H. Tabata, "Influence of microstructure on the complex permeability of spinel type Ni-Zn ferrite," J. Mag. Magn. Mater. 305, (1), 269-274, (2006). 
[23] T. K. Gupta and R. L. Coble, Sintering of ZnO: I, Densification and Grain Growth, J. Am. Ceram. Soc. 51, (9), 521-525 (1968).

[24] O. F. Caltun, L. Spinu, A. Stancu, L. Thung, and W. Zhou, Study of the microstructure and of the permeability spectra of Ni-Zn-Cu ferrites, J. Magn. Magn. Mater. 242-245, 160-162 (2002).

[25] K. Brinkman, T. Iijima, K. Nishida, T. Katoda, and H. Funakubo, The Influence of Acceptor Doping on the Structure and Electrical Properties of Sol-Gel Derived $\mathrm{BiFeO}_{3}$ Thin Films, Ferroelect. 357, (1), $35-40$ (2007).

[26] M. L. Neel, Nouvelle théorie du champ coercitif, Physica, 15, 225-234 (1949).

[27] F. U. Ahmed, S. M. Yunus, I. Kamal, T. K. Datta, A. K. Azad, and M. A. Asgar, Neutron Diffraction Study of $\mathrm{Zn}_{x} \mathrm{Ni}_{1-x} \mathrm{Fe}_{2} \mathrm{O}_{4}(x=0.25$ and 0.85) ferrite, Nucl. Sci. Appl. 7, (1,2), 7 (1998).

[28] E. C. Snelling, Soft ferrites: Properties and Applications, First Edition. London: Ilife Books Ltd. (1969).

[29] E. Rosses, I. Hanke, E. Moser, and Z. Angew, MnZn ferrites with initial permeability exceeding 20000 and their microstructures, Phys., 17, 504-508 (1964).

[30] D. J. Perduijin, H. P. Pel Oscheek, Proc. Br. Ceram. Soc., 10, 263 (1968).

[31] V. V. Awati, Sol-Gel Preparation, Synthesis and Characterization of Nano Structured $\mathrm{Cu}^{2+}$ Doped Ni-Zn Ferrite Material, Adv. Sci. Lett. 22, (4), 797-802 (2016).

[32] N. Gupta, M. C. Dimri, S. C. Kashyap, and D. C. Dube, Processing and properties of cobaltsubstituted lithium ferrite in the GHz frequency range, Ceram. Intern. 31, (1), 171-176 (2005).

[33] J. Shrotri, S. Kulkarni, C. Deshpande, A. Mitra, S. Sainkar, P. Anil Kumar, and S. Date, Effect of $\mathrm{Cu}$ substitution on the magnetic and electrical properties of $\mathrm{Ni}-\mathrm{Zn}$ ferrite synthesised by soft chemical method, Mater. Chemi. and Phys. 59, (1), 1-5 (1999).

[34] F. G. Brockman, P. H. Dowling, and W. G. Steneck, Dimensional Effects Resulting from a High Dielectric Constant Found in a Ferromagnetic Ferrite, Phys. Rev. 77, (1) 85-93 (1950).

[35] G. C. Allen, J. A. Jutson, and P. A. Tempest, Characterization of nickel-chromium-iron spinel-type oxides," J. Nucl. Mate. 158, 96-107 (1988).

[36] J. Chand, G. Kumar, P. Kumar, S. K. Sharma, M. Knobel, and M. Singh, Effect of Gd3+ doping on magnetic, electric and dielectric properties of $\mathrm{MgGd}_{\mathrm{x}} \mathrm{Fe}_{2-\mathrm{x}} \mathrm{O}_{4}$ ferrites processed by solid state reaction technique, J. Alloy. Comp. 509, (40), 9638-9644 (2011).

[37] K. Overshott, The causes of the anomalous loss in amorphous ribbon materials, IEEE Trans. Magn. 17, (6), 2698-2700 (1981).

[38] M. A. E. Hiti, A. I. E. Shora, and S. M. Hammad, Some physical properties of Mg-Zn ferrites, Mater. Sci. Tech. 13, (8), 625-630 (1997).

[39] M. B. Hossen and A. K. M. A. Hossain, AC resistivity and frequency dependence of the dielectric properties for $\mathrm{Al}$ doped NiCuZn ferrites, International Conf. Inform. Electron.Vision (ICIEV) (2012).

[40] B. P. RAO and K. H. RAO, Effect of sintering conditions on resistivity and dielectric properties of NiZn ferrites, J. Mater. Sci. 32, (22), 6049-6054 (1997).

[41] A. Globus and P. Duplex, Effective Anisotropy in Polycrystalline Materials: Separation of Components, J. Applied Phys. 39, (2), 727-729 (1968).

[42] K. R. Krishna, K. V. Kumar, and D. Ravinder, Structural and Electrical Conductivity Studies in Nickel-Zinc Ferrite, Adv. in Mater. Phys. Chemi. 02, (03), 185-191 (2012). 
[43] J. C. Maxwell, Electricity and magnetism, Oxford University Press, London (1973).

[44] S. S. Chougule and B. K. Chougule, Response of dielectric behavior and magnetoelectric effect in ferroelectric rich (x) $\mathrm{Ni}_{0.9} \mathrm{Zn}_{0.1} \mathrm{Fe}_{2} \mathrm{O}_{4}+(1-\mathrm{x}) \mathrm{PZT}$ ME composites, J. Alloy Comp. 456, (1-2), 441-446 (2008).

[45] H. Yang, H. Wang, L. He, L. Shui, and X. Yao, Polarization relaxation mechanism of $\mathrm{Ba}_{0.6} \mathrm{Sr}_{0.4} \mathrm{TiO}_{3} / \mathrm{Ni}_{0.8} \mathrm{Zn}_{0.2} \mathrm{Fe}_{2} \mathrm{O}_{4}$ composite with giant dielectric constant and high permeability, J. Appl. Phys. 108, (7), 074105 (2010).

[46] Y. D. Kolekar, L. J. Sanchez, and C. V. Ramana, Dielectric relaxations and alternating current conductivity in manganese substituted cobalt ferrite, J. Appl. Phys. 115, (14), 144106 (2014).

[47] N. Sivakumar, A. Narayanasamy, C. N. Chinnasamy, and B. Jeyadevan, Influence of thermal annealing on the dielectric properties and electrical relaxation behaviour in nanostructured $\mathrm{CoFe}_{2} \mathrm{O}_{4}$ ferrite, J.Phys. Cond. Matter. 19, (38), 386201 ( 2007). 